\title{
Saccharomyces cerevisiae biofilm tolerance towards systemic antifungals depends on growth phase
}

\author{
Rasmus Bojsen ${ }^{1,2^{*}}$, Birgitte Regenberg ${ }^{3}$ and Anders Folkesson ${ }^{2 *}$
}

\begin{abstract}
Background: Biofilm-forming Candida species cause infections that can be difficult to eradicate, possibly because of antifungal drug tolerance mechanisms specific to biofilms. In spite of decades of research, the connection between biofilm and drug tolerance is not fully understood.

Results: We used Saccharomyces cerevisiae as a model for drug susceptibility of yeast biofilms. Confocal laser scanning microscopy showed that S. cerevisiae and C. glabrata form similarly structured biofilms and that the viable cell numbers were significantly reduced by treatment of mature biofilms with amphotericin B but not voriconazole, flucytosine, or caspofungin. We showed that metabolic activity in yeast biofilm cells decreased with time, as visualized by FUN-1 staining, and mature, 48-hour biofilms contained cells with slow metabolism and limited growth. Time-kill studies showed that in exponentially growing planktonic cells, voriconazole had limited antifungal activity, flucytosine was fungistatic, caspofungin and amphotericin B were fungicidal. In growth-arrested cells, only amphotericin B had antifungal activity. Confocal microscopy and colony count viability assays revealed that the response of growing biofilms to antifungal drugs was similar to the response of exponentially growing planktonic cells. The response in mature biofilm was similar to that of non-growing planktonic cells. These results confirmed the importance of growth phase on drug efficacy.

Conclusions: We showed that in vitro susceptibility to antifungal drugs was independent of biofilm or planktonic growth mode. Instead, drug tolerance was a consequence of growth arrest achievable by both planktonic and biofilm populations. Our results suggest that efficient strategies for treatment of yeast biofilm might be developed by targeting of non-dividing cells.
\end{abstract}

Keywords: Yeast, Biofilm, Drug tolerance, Antifungal agent, Amphotericin B, Voriconazole, Flucytosine, Caspofungin, Fungicide, Resistance

\section{Background}

Nosocomial fungal infections are a major problem for immune compromised patients with a severe underlying disease [1]. Fungi can cause infections by colonizing mucosal surfaces in the oral cavity, airways, wounds and the gastrointestinal tract [2]. Fungi can also adhere to invasive medical devices and cause severe septicemia upon detachment [3]. The hallmarks of biofilms are surface attachment and production of an extracellular matrix (ECM) [4]. Failure to eradicate microbial infections is

\footnotetext{
* Correspondence: rakb@vet.dtu.dk; afol@vet.dtu.dk

'Department of Systems Biology, Technical University of Denmark, Kgs.

Lyngby, Denmark

${ }^{2}$ National Veterinary Institute, Technical University of Denmark, Frederiksberg, Denmark

Full list of author information is available at the end of the article
}

often attributed to the unique lifestyle of cells in biofilms and it is widely accepted that cells in a biofilm possess antimicrobial tolerance mechanisms that are distinct from their planktonic counterparts [2].

Drugs currently being used to treat systemic mycoses belong to four major classes. The azoles target cytochrome P450 and inhibit cell membrane ergosterol biosynthesis, resulting in accumulation of toxic ergosterol intermediates [5]. Azoles have poor efficacy against Candida species other than C. albicans, such as C. glabrata [6]. The number of nosocomial blood isolates of these non-susceptible Candida species has increased in the past decades, possibly because of the selection that frequent azole use impose [7]. The echinocandins inhibit $1,3-\beta$-glucan synthases, resulting in a reduction in cell wall 1,3- $\beta$-glucan [8], and the polyenes target ergosterol 
and cause pore formation in the fungal cell membrane [9]. The fourth class is the antimetabolite flucytosine. Flucytosine is deaminated upon uptake in susceptible cells and converted to 5-fluorouridine triphosphate, which is incorporated into RNA, inhibiting protein synthesis [10]. Flucytosine can also be converted to 5-fluorodeoxyuridine monophosphate which acts on thymidylate synthase to inhibit DNA synthesis [10]. Despite the pronounced diversity in antifungal mechanism of action and chemical structure, most antifungal agents are inactive against fungal biofilms [11].

Several mechanisms have been suggested to be responsible for drug tolerance of yeast biofilms. One of them is the ECM layer that contains $\beta-1,3$ glucans and extracellular DNA [12,13]. Treatment of biofilm cells with glucanases or DNase result in increased efficacy of antifungal agents, which indicate a role of ECM on antifungal drug tolerance $[13,14]$. However, it has been shown that antifungal susceptibility is independent of amount of matrix produced and antifungal drugs can diffuse through the matrix layer in inhibitory concentrations $[15,16]$. The ECM, in combination with the nutrient-limited environment that results from a large number of microbial cells, might induce expression of genes that help cells cope with stressful conditions. Altered gene expression could involve differential regulation of general stress-response genes that affect drug tolerance. For example, efflux pumps are reported to be upregulated in young and intermediate $[17,18]$ biofilms in Candida species. However, efflux pump knockout mutants remain drug resistant $[18,19]$ and up-regulation is lost in mature biofilms [17,18]. Furthermore, since polyenes and echinocandins are not a substrate of any known efflux pumps [20], efflux pumps are not responsible for biofilm-mediated tolerance to these drug classes. None of the suggested tolerance mechanisms are solely responsible for the multidrug tolerance associated with biofilm, and it might be a combination of several individual mechanisms that cause multidrug tolerance in yeast biofilms.

Candida is the most frequent cause of fungal infections and extensive research has been performed with this organism to investigate regulation of biofilm formation and antifungal drug recalcitrance [3]. However, due to a limited repertoire of genetic and molecular techniques available for some Candida species, the knowledge about yeast biofilm regulation and drug tolerance is incomplete. The genetic tractability of another fungus, Saccharomyces cerevisiae, has made it a model organism for the study of fundamental issues in fungal biology [21]. Transition from yeast to filamentous morphology is correlated to virulence in Candida albicans and key signaling pathways controlling this process is conserved in S. cerevisiae [22]. Candida glabrata is phylogenetically more closely related to $S$. cerevisiae than to other Candida species [23] and they have homologous cell-surface adhesins [24]. C. glabrata and S. cerevisiae furthermore form biofilms as haploids with similar biofilm architecture: thin layer of biofilm cells with yeast morphotype surrounded by a low density of ECM $[25,26]$. S. cerevisiae is therefore relevant for the study of $C$. albicans virulence and C. glabrata biofilm. S. cerevisiae has previously been used as a model organism to study yeast biofilm development and regulation by taking advantage of the molecular tools available for this organism [27-33]. However, much less effort has been made to investigate the response of $S$. cerevisiae biofilm cells to antifungal treatment $[32,34,35]$. S. cerevisiae has the potential to cause human infections [36] and its ability to adhere to plastic surfaces $[28,30]$ makes it a relevant organism for the study of yeast biofilm tolerance towards antifungal agents.

Fungal and bacterial research report 1000-fold higher tolerance level of mature biofilms compared to proliferating planktonic populations $[37,38]$. Research in bacteria has shown that the tolerance phenotype is similar between biofilm and planktonic cells when cultivated for equally long time in identical medium [39-41]. This indicates that tolerance mechanisms are not biofilm-specific and that planktonic cells can achieve the same level of tolerance. To address if growth arrest is also relevant for drug tolerance in yeast biofilm, we have compared susceptibility of common antifungals in biofilms and planktonic cells cultivated under similar conditions. We used in vitro biofilms of $S$. cerevisiae and C. glabrata cultures to investigate antifungal tolerance to drugs from each of the major antifungal drug classes used for systemic treatment of human pathogenic fungal infections: the polyene amphotericin $\mathrm{B}(\mathrm{AmB})$, the azole voriconazole (VOR), the antimetabolite flucytosine (5FC), and the echinocandin caspofungin (CAS). We found that the ability of biofilms to survive antifungal treatment was dependent on the mode of action of the antifungal agent and the growth state of the yeast cells.

\section{Results}

\section{S. cerevisiae and C. glabrata biofilms have similar} structure and antifungal tolerance

We initially determined antifungal drug susceptibilities of exponentially growing planktonic S. cerevisiae and $C$. glabrata cells towards four antifungal compounds, AmB, VOR, 5FC, and CAS. Drug susceptibilities of S. cerevisiae cells were similar to C. glabrata as determined by minimal inhibitory concentrations (MIC), except for VOR that was $4 \mu \mathrm{g} / \mathrm{ml}$ against C. glabrata, and $1 \mu \mathrm{g} / \mathrm{ml}$ against $S$. cerevisiae (Table 1).

Yeast biofilm architecture and antifungal drug sensitivity was investigated using confocal laser scanning 
Table 1 MIC susceptibility pattern of antifungal agents against S. cerevisiae and C. glabrata

\begin{tabular}{|c|c|c|c|c|}
\hline \multirow[t]{2}{*}{ Organism } & \multicolumn{4}{|c|}{$\mathrm{MIC}(\mu \mathrm{g} / \mathrm{ml})$} \\
\hline & VOR & $5 \mathrm{FC}$ & CAS & $\mathrm{AmB}$ \\
\hline S. cerevisiae & 1 & 8 & 1 & 1 \\
\hline C. glabrata & 4 & 8 & 0.5 & 2 \\
\hline
\end{tabular}

VOR: voriconazole, 5FC: flucytosine, CAS: caspofungin, $A m B$ : amphotericin B.

microscopy (CLSM). Mature GFP-tagged biofilm cells were challenged with an antifungal agent for 24 hours and stained with propidium iodide (PI) to identify dead cells. S. cerevisiae biofilms contained a thin layer of cells (approximately $30 \mu \mathrm{m}$ ) with a few dead cells distributed throughout the biofilm. Biofilms treated with VOR, 5FC, or CAS had the same architecture and mixture of living and dead cells as untreated control cells (Figure 1), showing that the drugs were inactive against yeast biofilms. AmB was the only tested drug with anti-biofilm activity, killing most cells after 24 hours (Figure 1). The small subpopulation of cells that survived AmB treatment was randomly distributed in the biofilms.

To determine if results from the S. cerevisiae biofilm model applied to drug susceptibility in a pathogenic yeast, we investigated the antifungal drug susceptibility of C. glabrata biofilms. C. glabrata was cultivated under conditions similar to S. cerevisiae cultures and developed a thin layer of biofilm cells (approximately $25 \mu \mathrm{m}$ ). After 48 hours, mature biofilms were challenged with an antifungal drug for 24 hours and stained with Syto9 and PI to visualize living and dead cells. Results were similar to those obtained with S. cerevisiae. Most C. glabrata biofilm cells exposed to VOR, 5FC or CAS showed living cells with a few dead cells distributed in the biofilm, similar to the appearance of the untreated control cells (Figure 1). AmB treatment killed most cells with a small, surviving subpopulation randomly distributed in the biofilm. These results suggested that $S$. cerevisiae could be used as a model organism to study antifungal tolerance in biofilms of the pathogenic C. glabrata.

\section{Metabolic activity of biofilm cells decreases with biofilm maturity}

Planktonic microbial cells cultivated in a closed system take up nutrients from the environment and enters a stationary growth state with decreased metabolic activity when nutrients become limited. To investigate if the metabolic activity of biofilms at 48 hours was reduced compared to a 4 hour biofilm, we measured metabolic activity using FUN-1 staining. FUN-1 permeabilizes the plasma membrane and biochemical processing of the dye by an unknown pathway identifies metabolically active cells with intravacuolar structures [42]. Most cells in a 4-hour biofilm showed high metabolic activity as estimated by staining intensity of the vacuole (red color, Figure 2), but staining decreased with biofilm incubation time. After 48 hours, only a small subpopulation of cells in the biofilms showed FUN-1 staining of vacuoles indicating a lower or different metabolic activity in mature biofilm than that found in young 4 hour biofilm (Figure 2).

\section{Activity of antifungal drugs depends on growth state}

We hypothesized that the limited metabolic activity and resulting lack of growth observed in cells in mature biofilms may be an important cause of the low antifungal activity of the drugs tested. We measured therefore the killing kinetics of the antifungals using an exponentially growing planktonic population and a growth-arrested planktonic population. Untreated control cells proliferated with a doubling time of 1.5 hours in the exponential growth phase for the first 8 hours of incubation (Figure 3A). The density of cells exposed to VOR increased at the same rate as the untreated sample for the first 7 hours of incubation. Subsequently, the azole drug inhibited growth, resulting in a decrease in viability after 24 hours. After two hours of exposure to $5 \mathrm{FC}$, the growth of exponential phase populations was inhibited and cells remained at the same viability and density for 24 hours showing that $5 \mathrm{FC}$ had fungistatic activity. CAS had an inhibitory effect on exponential growth within the first hours of exposure and a consistent killing rate throughout the experiment that resulted in a 10-fold reduction in colony forming units (CFUs) after 24 hours compared to the initial population. Challenging cultures with $\mathrm{AmB}$ rapidly decreased the viable population, reaching the lower detection limit for CFUs after 5 hours.

We next investigated how growth arrest affects susceptibility to antifungal agents by incubating cells in carbon-depleted medium. Starting cell density was similar to the starting density used for time-kill studies on the exponential growing populations to eliminate cell numbers from affecting comparisons between the two experiments. Growth-arrested S. cerevisiae exposed to VOR, 5FC or CAS had viability similar to untreated control cells, showing that the drugs had no activity against non-growing cells in stationary phase (Figure 3B). Cells exposed to $\mathrm{AmB}$ were killed, but the killing rate was lower than the rate observed for exponentially growing cells. The lower detection limit for CFUs was not reached in the first 8 hours of drug exposure, but only after 24 hours.

\section{Drug sensitivity restored in a growing biofilm population} The antifungal activity of 5FC, CAS and AmB against exponentially growing planktonic $S$. cerevisiae, but not against growth-arrested cells, suggested that drug activity depended on cell growth. To test if growth-dependent 


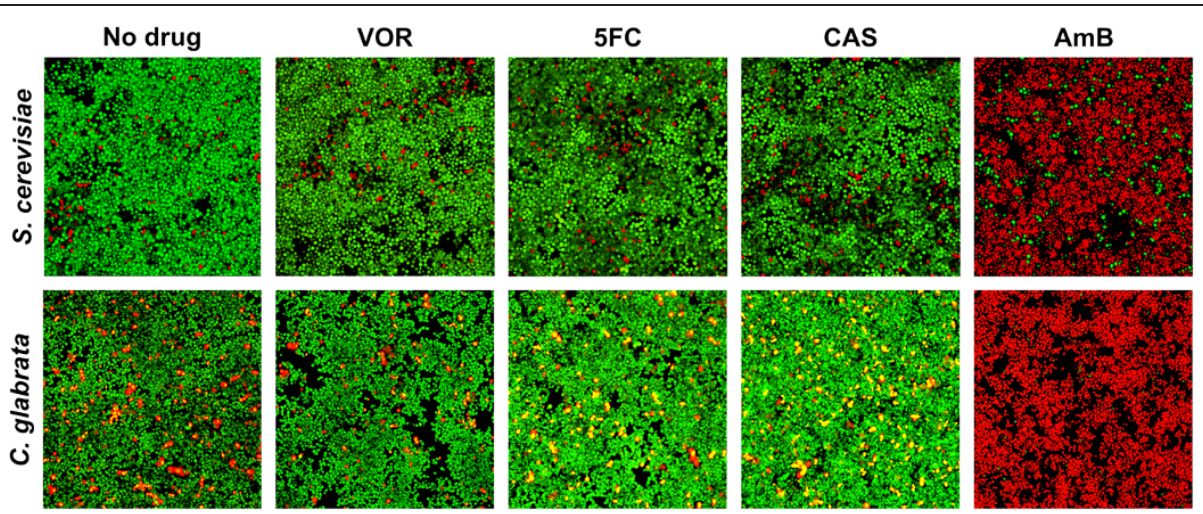

Figure 1 Mature S. cerevisiae and C. glabrata biofilms have similar sensitivity to antifungal drugs. Antifungal drug activity against 48-hour biofilms was visualized by confocal laser scanning microscopy. GFP-tagged S. cerevisiae was stained with propidium iodide (PI, $1 \mu \mathrm{M})$ to mark living (green) and dead (red) cells. C. glabrata was stained with Syto9 $(3 \mu \mathrm{M})$ and PI (1 $\mu \mathrm{M})$ to mark living (green) and dead (red/yellow) cells. Biofilm cells were treated for 24 hours with the indicated antifungal agents. VOR: voriconazole ( $10 \mu \mathrm{g} / \mathrm{ml}$ for S. cerevisiae and $50 \mu \mathrm{g} / \mathrm{ml}$ for C. glabrata), 5FC: flucytosine $(80 \mu \mathrm{g} / \mathrm{ml})$, CAS: caspofungin $(10 \mu \mathrm{g} / \mathrm{ml}$ for S. cerevisiae and $5 \mu \mathrm{g} / \mathrm{ml}$ for C. glabrata), and AmB: amphotericin B $(10 \mu \mathrm{g} / \mathrm{ml}$ for S. cerevisiae and $20 \mu \mathrm{g} / \mathrm{ml}$ for C. glabrata).

drug activity also applied to cells in biofilms, the viability of a growing $S$. cerevisiae biofilm was quantified as CFUs and visualized with CLSM. Quantification and visualization assays were conducted after 24 hours of drug treatment. The number of cells in untreated 4-hour biofilms increased 8-fold over 24 hours, as determined by CFUs (Figure 4). Growth in 4-hour biofilms exposed to VOR or $5 F C$ was inhibited compared to untreated control biofilms. Cell numbers determined by CFUs increased 3-fold with VOR treatment and 1.3-fold with 5FC treatment. In contrast, $80 \%$ of biofilm cells exposed to CAS were killed, with surviving cells sporadically distributed in the biofilm (Figure 4). AmB had a fungicidal effect on young biofilms, killing $99.7 \%$ of cells during a 24-hour exposure. Biofilms treated with AmB still contained minor surviving subpopulations (Figure 4).
Mature biofilm and stationary planktonic yeast have similar susceptibility to systemic antifungals

We observed that most drug classes tested in this study were inactive against mature biofilms (Figure 1) and planktonic cells that are arrested for growth (Figure 3), whereas growing biofilm and planktonic cells were susceptible to both AmB, VOR, 5FC, and CAS. These data suggest that the physiological state of the cell in response to ceased proliferation, rather than a biofilm-specific response mediate drug tolerance in yeast biofilms.

To determine the effect of growth arrest on drug tolerance, we investigated differences in antifungal drug susceptibility between stationary cultures of cells grown planktonically or in biofilms for 48 hours. S. cerevisiae biofilms were cultivated on flat polystyrene surfaces. For planktonic control populations, S. cerevisiae was cultivated

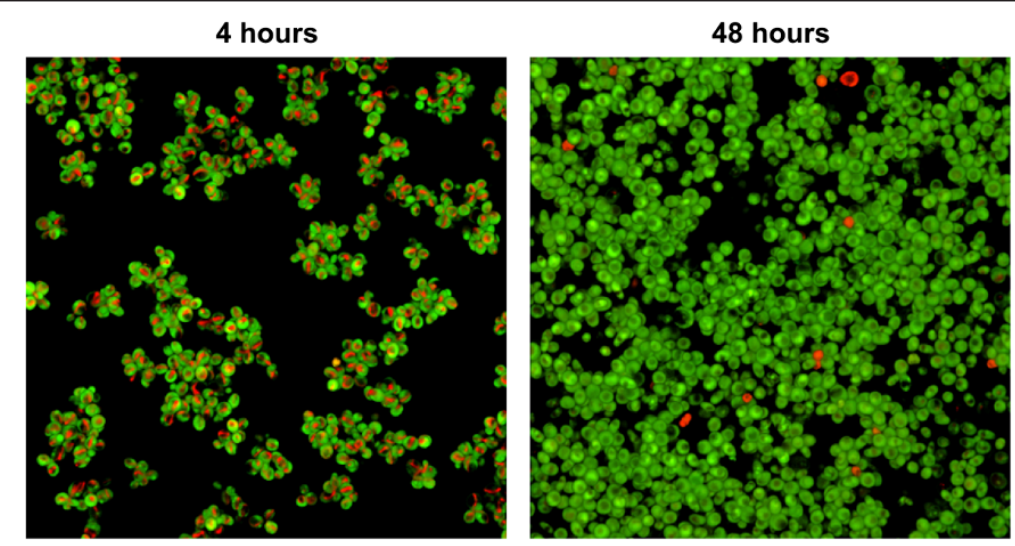

Figure 2 Metabolic activity of yeast cells in biofilms decreases with incubation time. S. cerevisiae cells stained with FUN-1 (10 $\mu M)$ after incubation of biofilm for 4 hours and 48 hours respectively. Metabolically active cells produce red cylindrical intravacuolar structures. 

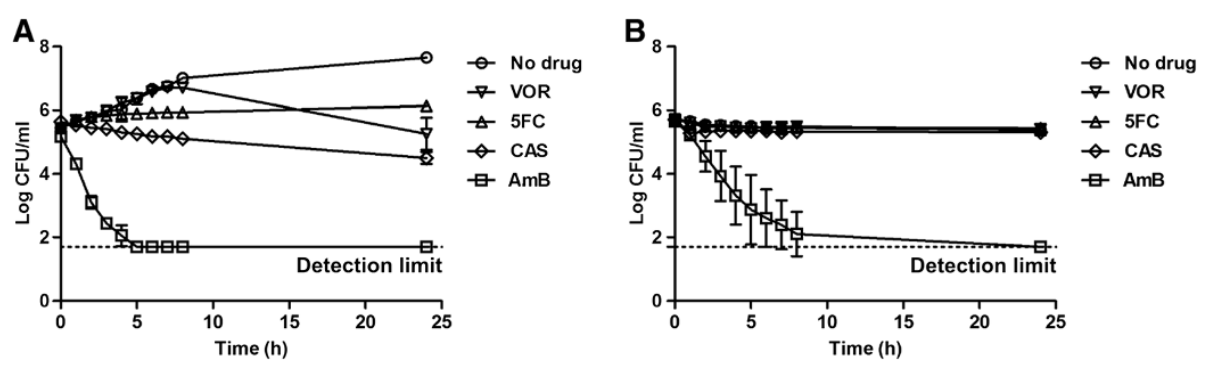

Figure 3 Antifungal drug susceptibility in exponentially growing and growth arrested planktonic cells. (A) Killing kinetics of exponentially growing planktonic S. cerevisiae cultivated in $2 \%$ glucose exposed to 5 times the MIC of the indicated antifungal drugs. (B) Killing kinetics of growth-arrested planktonic S. cerevisiae cultivated in carbon-depleted minimal medium exposed to 5 times MIC of the indicated antifungal drugs. VOR: voriconazole $(5 \mu \mathrm{g} / \mathrm{ml})$, 5FC: flucytosine $(40 \mu \mathrm{g} / \mathrm{ml})$, CAS: caspofungin $(5 \mu \mathrm{g} / \mathrm{ml})$, AmB: amphotericin B $(5 \mu \mathrm{g} / \mathrm{ml})$. $\mathrm{n}=3$, error bars show standard deviations.

in glass tubes [43]. An isogenic biofilm-deficient flo11 knockout mutant was included as a negative control for biofilm formation [28]. The average inoculum before drug challenge was $1.6 \times 10^{7} \mathrm{CFU} / \mathrm{ml}$ for biofilm cells, $1.8 \times 10^{7}$ for planktonic cells and $7.5 \times 10^{6}$ for flo11, minimizing the influence of different cell densities on drug susceptibility between the cultivation assays.

All three cultures, biofilm, flo11 control, and planktonic, were challenged for 24 hours with antifungal agents. No significant effects on CFUs were seen after treatment with VOR, 5FC, or CAS (Figure 5), indicating that growth arrested S. cerevisiae was not susceptible to any of the drugs under any of the three growth conditions. Only treatment with AmB significantly decreased population sizes $(\mathrm{P}<0.01$, Student's $t$-test). Exposure to AmB killed $95-98 \%$ of the yeast populations regardless of growth condition (Figure 5). However, in all three growth conditions, a subpopulation of $2-5 \%$ of cells survived drug treatment, so $\mathrm{AmB}$ was unable to eradicate the entire S. cerevisiae population.

\section{Discussion}

In the current study, we found that antifungal drug efficacy against $S$. cerevisiae biofilm was dependent on cell
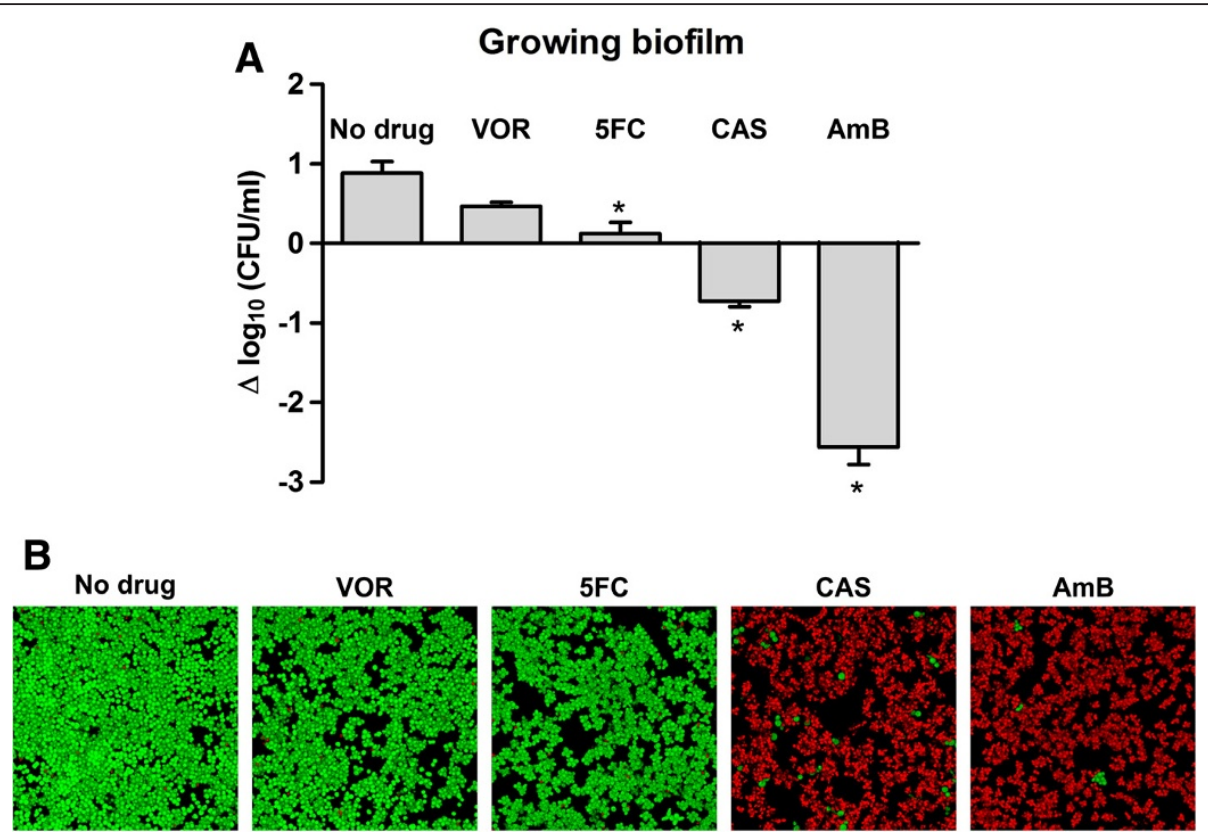

Figure 4 Antifungal drugs are active against growing biofilms. (A) Quantitation of biofilm cell viability. Biofilms were grown for 4 hours and viability determined as CFUs. Biofilms were then treated with 10 times the MIC of the indicated antifungal drug for 24 hours and CFUs were measured. Shown is log change in CFUs after 24 hours treatment. $n=3$, error bars are standard deviations. Statistical significance between treated and untreated samples was evaluated with Student's t-test. ${ }^{*} P<0.01$. (B) GFP-tagged S. cerevisiae in 4-hour biofilms treated for 24 hours with the indicated antifungal agents. VOR: voriconazole $(10 \mu \mathrm{g} / \mathrm{ml})$, 5FC: flucytosine $(80 \mu \mathrm{g} / \mathrm{ml})$, CAS: caspofungin $(10 \mu \mathrm{g} / \mathrm{ml})$, and AmB: amphotericin B $(10 \mu \mathrm{g} / \mathrm{ml})$. Cells were visualized as described in the legend to Figure 1. 


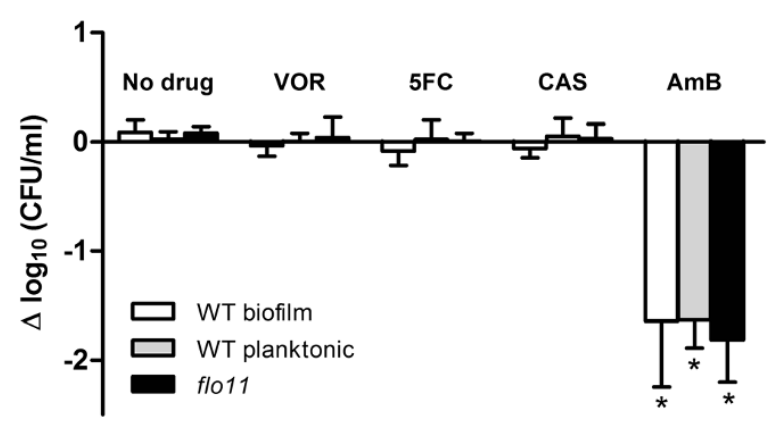

Figure 5 Stationary S. cerevisiae cells grown in biofilms and planktonic cultures have similar drug tolerance. Cultures were grown for 48 hours and viability was measured as CFUs. Cells were treated with 10 times MIC of the indicated antifungal drug, or left untreated as a control, and CFUs were measured after 24 hours. Shown is log change in viability. White bar: wild type $S$. cerevisiae $\sum 1278 \mathrm{~b}$ grown as biofilms on polystyrene surfaces. Grey bar: wild type grown planktonically in glass flasks. Black bar: flo 11 knockout mutant grown planktonically in glass flasks. VOR: voriconazole $(10 \mu \mathrm{g} / \mathrm{ml})$, 5FC: flucytosine $(80 \mu \mathrm{g} / \mathrm{ml})$, CAS: caspofungin $(10 \mu \mathrm{g} / \mathrm{ml})$, AmB: amphotericin B $(10 \mu \mathrm{g} / \mathrm{ml}) . \mathrm{n}=3$, error bars show standard deviation. Statistical significance between treated and untreated samples was evaluated with Student's t-test. ${ }^{*} P<0.01$.

growth. Only growing S. cerevisiae cells were susceptible to growth inhibition by the fungistatic drugs VOR and 5FC, and killing by CAS. However, S. cerevisiae cells in both growing and stationary state were efficiently killed by AmB. We further observed that the effects of antifungals were independent of biofilm or planktonic modes of growth.

Multidrug tolerance mechanisms in biofilms are suggested to include production of an ECM and a densely packed microbial structure that shields cells, preventing antimicrobials from reaching their targets. Cell-surface proteins in the Flo family are responsible for S. cerevisiae adhesion and ECM production [44]. Flo11p is the only flocculation protein expressed in the $\Sigma 1278 \mathrm{~b}$ S. cerevisiae strain and it is essential for biofilm formation in liquid medium [28,44-46]. We showed that a flo11 mutant has an antifungal tolerance phenotype that is similar to mature yeast biofilms (Figure 5). This finding suggests that cell-cell adhesion and Flo11p-dependent matrix production are not obstacles for cell penetration by antifungal drugs in S. cerevisiae biofilm. This observation is in contrast to the drug sequestering role of matrix $\beta-1,3$ glucan in Candida biofilms [13,47,48] and might reflect differences in matrix composition between $\Sigma 1278$ b S. cerevisiae and Candida biofilms. The ECM layer is, however, not the sole contributor to the drug tolerant phenotype because systemic antifungals can penetrate the ECM of Candida species biofilms at concentrations that exceed the MIC values, and no correlation is observed between the amount of matrix produced and drug susceptibility
$[15,49]$. In agreement with this, our results show similar drug susceptibility between S. cerevisiae and C. glabrata biofilms, suggesting another important contributor to the observed antifungal drug tolerance phenotype.

Heterogeneous microbial biofilms often contain large subpopulations with low metabolic activity [50,51]. We showed that the metabolic activity of most cells in yeast biofilms decreased as the biofilm matured (Figure 2) and we observed no increase in cell density in mature biofilms (Figure 5A). Therefore, large fractions of cells in mature biofilms are likely in a stationary state. Even though antimicrobial agents have diverse modes of action, most are dependent on active growth to kill cells [52], which we confirmed in the present study.

The drug 5FC has fungistatic activity against Candida species [53]. We found a similar fungistatic activity against proliferating S. cerevisiae $\Sigma 1278$ b planktonic and biofilm populations (Figure 3A and Figure 4). However, 5FC was inactive against mature biofilms and growth arrested planktonic cells (Figures 1, 3B and 5). This result is not surprising since fungistatic drugs do not kill cells but only inhibit proliferation. Therefore, the viability of highdensity, nongrowing microbial populations such as mature biofilms or stationary phase planktonic cells is expected to be unaffected by treatment with fungistatic drugs.

Echinocandins have fungicidal activity against Candida species [54] and we found that CAS killed 90\% of exponential growing planktonic S. cerevisiae cells (Figure 3A) and $80 \%$ of proliferating biofilm cells (Figure 4). Despite the ability of CAS to kill exponentially growing yeast cells, CAS had no activity against mature biofilms (Figures 1 and 5). CAS inhibits $1,3-\beta$-glucan synthase, which disrupt the yeast cell wall and result in osmotic stress and cell lysis [8]. However, the synthase is most active in growing cells $[55,56]$, so CAS is unable to kill growth-arrested cells [54] as we observed in this study (Figure 3B) including the cells in mature biofilms.

The polyene AmB was the only drug tested in this study with activity against cells in mature biofilms (Figures 1 and 5) and growth arrested planktonic cells (Figure 3B). $\mathrm{AmB}$ binds to ergosterol in the cell membrane and form pores that increase the permeability of electrolytes and small molecules. Pore formation results in loss of membrane potential and eventually cell lysis [9]. Since ion diffusion and lysis are passive processes, cell metabolism is not required for $\mathrm{AmB}$ to kill cells. Consistent with this mechanism, AmB killed both growing and non-growing yeast cells (Figure 3 ). However, although AmB killed cells in non-proliferating, low-density yeast populations, AmBtolerant subpopulations were observed in stationary state planktonic and biofilm populations (Figure 5).

Azole drugs are fungistatic against $C$. albicans, but less active against other Candida species, which show a clear increase in cell density after azole treatment $[57,58]$. The 
poor efficacy of the azole drug VOR against $S$. cerevisiae cells within the first 7 hours of exposure (Figure 3A) might be because $S$. cerevisiae and the closely related C. glabrata share a mechanism that makes them intrinsically resistant to azoles.

Bacterial cells grown as biofilms or grown to stationary state as planktonic cells have similar drug-tolerance phenotypes $[40,41,59,60]$; we have in the present study extended this phenotypic similarity to include yeast. Our results indicated that the biofilm mode of growth itself does not result in antifungal tolerance. Rather, the lack of cell division and the physiological state of stationary phase cells is responsible for the drug-tolerant phenotype.

\section{Conclusions}

A combination of factors is probably responsible for the multidrug tolerance of cells in biofilms. However, as long as biofilm populations contain non-proliferating cells, some of the most commonly used antimicrobials will have reduced efficacy. Biofilm tolerance to drugs is conditional and depends on the mode of action of the tested drugs, as well as cell physiology and environment [61]. We showed that standard laboratory yeast biofilm models and methods can determine cell culture conditions under which antifungal drugs are effective or ineffective. Our findings imply that biofilm tolerance phenotypes might be caused by the large number of stationary cells within mature biofilms rather than specific biofilm mechanisms. Our data therefore suggest that future research on novel drugs and treatments should focus on strategies that are effective against stationary non-growing cells, rather than attempting to develop specific anti-biofilm treatments. The results obtained in this study are based on in vitro experiments and relies on the value of $S$. cerevisiae as a model organism for the pathogenic fungi. Our results indicate that $S$. cerevisiae and C. glabrata biofilms have similar antifungal sensitivity, but the results should also be verified in an in vivo model.

\section{Methods}

\section{Yeast strains}

S. cerevisiae $\Sigma 1278 \mathrm{~b}$ YS-11 (MATa can1 $:: S T E 2 p$-spHIS5 lyp1A::STE3p-LEU2 his3::HisG leu2A ura3A) was used as reference strain (a gift from the Boone Laboratory, University of Toronto). A flo11 mutant that does not form biofilm was obtained from the $\Sigma 1278 \mathrm{~b}$ gene deletion library [27]. C. glabrata (ATCC 90030) was obtained from the American Type Culture Collection. A strain expressing green fluorescent protein (GFP) was constructed by expressing the GFP gene from the TEF1 promoter. The TEF1 promoter was PCR amplified from pSP-GM2 [62] with primers TEF-F: 5'-CGTGCGAUGCCGCACACAC CATAGCTTC and TEF-R: 5'ACGTATCGCUGTGAG
TCGTATTACGGATCCTTG. GFP was amplified from pJBA27a [63] with primers GFP-F: 5'-AGCGATACGUAG CATGCGTAAAGGAGAAGAA and GFP-R: 5'-CACGC GAUTATTTGTATAGTTCATCCATGCC. The GFP and TEF1 DNA fragments were simultaneously fused and cloned into a digested vector with USER (uracil-specific excision reagent) technology as previously described $[64,65]$. In short, the vector pXI-2 [66] was digested with AsiSI and nicking enzyme Nb.BsmI. Ten $\mu \mathrm{l}$ of digested vector was mixed with $5 \mu$ l of each DNA fragment, $1 \mu$ l USER enzyme and $1.5 \mu \mathrm{l}$ mili-Q water. The mix was incubated for 25 minutes at $35^{\circ} \mathrm{C}$ followed by 25 minutes at $25^{\circ} \mathrm{C}$. Subsequently, the reaction mixture was used directly to transform competent Escherichia coli cells (DH $\alpha 5)$. The resulting plasmid was denoted pRKB5. The TEF1pGFP fragment was inserted in chromosome XI position $(91,575 . .92,744)$ of the reference strain using a highefficiency transformation protocol [67] and transformants selected on synthetic complete agar medium that did not contain uracil.

\section{Media and antifungals}

All experiments were performed in synthetic complete medium $(0.67 \%$ yeast nitrogen base supplemented with glucose and amino acids) [68], which is the standard medium for the study of S. cerevisiae biofilms [28]. A $0.2 \%(\mathrm{w} / \mathrm{v})$ glucose concentration was used in all biofilm experiments. Yeast extract peptone dextrose (YPD) [68] agar plates were used for colony counting. Antifungals VOR, 5FC, AmB and CAS were from Sigma-Aldrich. All antifungals were dissolved in DMSO in $5 \mathrm{mg} / \mathrm{ml}$ stock solutions and stored at $-20^{\circ} \mathrm{C}$. All experiments were performed in triplicate.

\section{Minimal inhibitory concentration}

Minimal inhibitory concentrations (MIC) were determined as previously described [69] with modifications. In short, two-fold dilution series of antifungal drugs were prepared in fresh synthetic complete medium with $2 \%$ glucose $(\mathrm{w} / \mathrm{v})$ and distributed into 96-well microtiter plate. Synthetic RPMI medium is recommended for MIC assays by EUCAST, but S. cerevisiae grows poorly in RPMI and MIC was therefore determined in synthetic complete medium. Visibly turbid overnight cultures were diluted to $\mathrm{OD}_{600} 0.1$ in fresh medium and transferred to microtiter plates containing aliquots of serially diluted antifungal drug. Plates were statically incubated at $30^{\circ} \mathrm{C}$ for $24 \mathrm{~h}$ and absorbance was measured with a microplate spectrophotometer (BioTek PowerWave 340). Growth inhibition of $\geq 50 \%$ was determined as MIC for CAS, VOR and $5 F C$ and $\geq 90 \%$ growth inhibition was determined as MIC for AmB as recommended by EUCAST [69]. 


\section{Visualization of biofilm drug susceptibility}

Visibly turbid cultures were diluted to $\mathrm{OD}_{600}$ 0.1. After 2 hours at $30^{\circ} \mathrm{C}$, cells were transferred to biofilm chambers (Technical University of Denmark) with a polyvinyl chloride (PVC) coverslip surface (Rinzl, Electron Microscopy Sciences). After 4 or 48 hours static incubation at $30^{\circ} \mathrm{C}$, medium was removed from biofilm chambers and centrifuged and antifungal drug was added to the supernatants at 10 times the MIC. Spent medium with drug was introduced to biofilm cultures followed by 24 hours at $30^{\circ} \mathrm{C}$. Chromosomally integrated GFP and $3 \mu \mathrm{M}$ Syto9 (Invitrogen) were used to visualize live cells and $1 \mu \mathrm{M}$ propidium iodide (Sigma-Aldrich) was used to stain dead cells. CLSM was performed with a Zeiss LSM710 microscope equipped with excitation lasers at $488 \mathrm{~nm}$ and $514 \mathrm{~nm}$. Imaging used an EC Plan-Neofluar 40x/1.30 Oil lens.

\section{Metabolic activity}

Preparation of cell cultures and CLSM imaging was as described above except a Plan-Apochromat 63x/1.40 Oil DIC M27 objective was used. Metabolically active cells were distinguished from inactive cells with $10 \mu \mathrm{M}$ FUN-1 as described by the manufacturer (Molecular Probes, Probes for yeast viability, MP 07009). Cells were considered metabolic active if they produced red cylindrical intravacuolar structures $[42,51]$.

\section{Killing kinetics}

Overnight cultures were diluted to $\mathrm{OD}_{600} 0.01$ in fresh synthetic medium. Yeast cultures were grown to exponential phase in baffled shake flasks at $30^{\circ} \mathrm{C}$ and samples were distributed to test tubes for exposure to antifungal drugs at 5 times the MIC before incubation at $30^{\circ} \mathrm{C}$ with aeration. Samples were extracted at indicated time-points. CFUs were determined by plating serial dilutions on YPD agar.

\section{Antifungal survival assay}

Visibly turbid cultures were diluted to $\mathrm{OD}_{600} 0.1$ in synthetic medium and grown in baffled shake flasks for 2 hours. Culture samples were distributed to glass tubes for planktonic cells and polystyrene microtiter plates for biofilms and incubated statically at $30^{\circ} \mathrm{C}$. After 4 or 48 hours, cells were challenged with antifungal drug at 10 times the MIC, added in spent medium, for 24 hours. Viable cells were determined by counting CFUs on YPD agar. Biofilm cells were washed twice in saline and CFU was determined.

\section{Statistical analysis}

Unpaired Student's $t$-test was used for statistical analysis. $\mathrm{P}<0.01$ was considered significant. All statistical calculations were performed using GraphPad Prism version 5.00 for Windows, GraphPad Software, San Diego California USA.

\section{Abbreviations}

VOR: Voriconazole; 5FC: Flucytosine; CAS: Caspofungin; AmB: Amphotericin B; ECM: Extracellular matrix; MIC: Minimal inhibitory concentration; PI: Propidium iodide; CLSM: Confocal laser scanning microscopy; CFU: Colony forming unit.

\section{Competing interests}

The authors declare that they have no competing interests.

\section{Authors' contributions}

$\mathrm{RB}, \mathrm{BR}$ and $\mathrm{AF}$ designed the experiments. RB performed the experiments. $R B, B R$ and $A F$ analyzed the data. RB, BR and $A F$ wrote the manuscript. All authors read and approved the final manuscript.

\section{Acknowledgments}

We thank Charlie Boone and Owen Ryan (University of Toronto) for the $\Sigma 1278$ b strains. We also thank Tomas Strucko (Technical University of Denmark) for GFP construct strategy design. This work was supported by the Danish Agency for Science Technology and Innovation is (FTP 10-084027).

\section{Author details}

${ }^{1}$ Department of Systems Biology, Technical University of Denmark, Kgs. Lyngby, Denmark. ${ }^{2}$ National Veterinary Institute, Technical University of Denmark, Frederiksberg, Denmark. ${ }^{3}$ Department of Biology, University of Copenhagen, Copenhagen, Denmark.

Received: 25 July 2014 Accepted: 20 November 2014

Published online: 04 December 2014

\section{References}

1. Tortorano AM, Tortorano AM, Peman J, Bernhardt H, Klingspor L, Kibbler CC, Faure O, Biraghi E, Canton E, Zimmermann K, Seaton S, Grillot R: Epidemiology of candidaemia in Europe: results of 28-month European Confederation of Medical Mycology (ECMM) hospital-based surveillance study. Eur J Clin Microbiol Infect Dis 2004, 23(4):317-322.

2. Ramage G, Williams C: The clinical importance of fungal biofilms. Adv Appl Microbiol 2013, 84:27-83.

3. Ramage G, Martinez JP, Lopez-Ribot JL: Candida biofilms on implanted biomaterials: a clinically significant problem. FEMS Yeast Res 2006, 6(7):979-986.

4. Costerton JW, Stewart PS, Greenberg EP: Bacterial biofilms: a common cause of persistent infections. Science 1999, 284(5418):1318-1322.

5. Vanden Bossche H, Koymans L, Moereels H: P450 inhibitors of use in medical treatment: focus on mechanisms of action. Pharmacol Ther 1995, 67(1):79-100.

6. Kanafani ZA, Perfect JR: Antimicrobial resistance: resistance to antifungal agents: mechanisms and clinical impact. Clin Infect Dis 2008, 46(1):120-128.

7. Horn DL, Neofytos D, Anaissie EJ, Fishman JA, Steinbach WJ, Olyaei AJ, Marr KA, Pfaller MA, Chang CH, Webster KM: Epidemiology and outcomes of candidemia in 2019 patients: data from the prospective antifungal therapy alliance registry. Clin Infect Dis 2009, 48(12):1695-1703.

8. Deresinski SC, Stevens DA: Caspofungin. Clin Infect Dis 2003, 36(11):1445-1457.

9. Mesa-Arango AC, Scorzoni L, Zaragoza O: It only takes one to do many jobs: Amphotericin $B$ as antifungal and immunomodulatory drug. Front Microbiol 2012, 3:286.

10. Waldorf AR, Polak A: Mechanisms of action of 5-fluorocytosine. Antimicrob Agents Chemother 1983, 23(1):79-85.

11. Kuhn DM, George T, Chandra J, Mukherjee PK, Ghannoum MA: Antifungal susceptibility of Candida biofilms: unique efficacy of amphotericin B lipid formulations and echinocandins. Antimicrob Agents Chemother 2002, 46(6):1773-1780

12. Martins M, Uppuluri $P$, Thomas DP, Cleary IA, Henriques M, Lopez-Ribot JL, Oliveira R: Presence of extracellular DNA in the Candida albicans biofilm matrix and its contribution to biofilms. Mycopathologia 2010, 169(5):323-331.

13. Nett J, Lincoln L, Marchillo K, Massey R, Holoyda K, Hoff B, VanHandel M, Andes D: Putative role of beta-1,3 glucans in Candida albicans biofilm resistance. Antimicrob Agents Chemother 2007, 51(2):510-520.

14. Martins M, Henriques M, Lopez-Ribot JL, Oliveira R: Addition of DNase improves the in vitro activity of antifungal drugs against Candida albicans biofilms. Mycoses 2012, 55(1):80-85 
15. Al-Fattani MA, Douglas LJ: Penetration of Candida biofilms by antifungal agents. Antimicrob Agents Chemother 2004, 48(9):3291-3297.

16. Vediyappan G, Rossignol T, D'Enfert C: Interaction of Candida albicans biofilms with antifungals: transcriptional response and binding of antifungals to beta-glucans. Antimicrob Agents Chemother 2010, 54(5):2096-2111.

17. Song JW, Shin JH, Kee SJ, Kim SH, Shin MG, Suh SP, Ryang DW: Expression of CgCDR1, CgCDR2, and CgERG11 in Candida glabrata biofilms formed by bloodstream isolates. Med Monde 2009, 47(5):545-548.

18. Mukherjee PK, Chandra J, Kuhn DM, Ghannoum MA: Mechanism of fluconazole resistance in Candida albicans biofilms: phase-specific role of efflux pumps and membrane sterols. Infect Immun 2003, 71(8):4333-4340.

19. Ramage G, Bachmann S, Patterson TF, Wickes BL, Lopez-Ribot JL: Investigation of multidrug efflux pumps in relation to fluconazole resistance in Candida albicans biofilms. J Antimicrob Chemother 2002, 49(6):973-980.

20. Cannon RD, Lamping E, Holmes AR, Niimi K, Baret PV, Keniya MV, Tanabe K, Niimi M, Goffeau A, Monk BC: Efflux-mediated antifungal drug resistance. Clin Microbiol Rev 2009, 22(2):291-321. Table of Content.

21. Botstein D, Fink GR: Yeast: an experimental organism for 21 st Century biology. Genetics 2011, 189(3):695-704.

22. Shapiro RS, Robbins N, Cowen LE: Regulatory circuitry governing fungal development, drug resistance, and disease. Microbiol Mol Biol Rev: MMBR 2011, 75(2):213-267.

23. Dujon B, Sherman D, Fischer G, Durrens P, Casaregola S, Lafontaine De Montigny J, Marck C, Neuveglise C, Talla E, Goffard N, Frangeul L, Aigle M, Anthouard V, Babour A, Barbe V, Barnay S, Blanchin S, Beckerich JM, Beyne E, Bleykasten C, Boisrame A, Boyer J, Cattolico L, Confanioleri F, De Daruvar A, Despons L, Fabre E, Fairhead C, Ferry-Dumazet $\mathrm{H}$, et al: Genome evolution in yeasts. Nature 2004, 430(6995):35-44.

24. Verstrepen KJ, Klis FM: Flocculation, adhesion and biofilm formation in yeasts. Mol Microbiol 2006, 60(1):5-15

25. Seneviratne CJ, Silva WJ, Jin L, Samaranayake YH, Samaranayake LP: Architectural analysis, viability assessment and growth kinetics of Candida albicans and Candida glabrata biofilms. Arch Oral Biol 2009, 54(11):1052-1060.

26. Hawser SP, Douglas LJ: Biofilm formation by Candida species on the surface of catheter materials in vitro. Infect Immun 1994, 62(3):915-921.

27. Ryan O, Shapiro RS, Kurat CF, Mayhew D, Baryshnikova A, Chin B, Lin ZY, Cox MJ, Vizeacoumar F, Cheung D, Bahr S, Tsui K, Tebbji F, Sellam A, Istel F, Schwarzmuller T, Reynolds TB, Kuchler K, Gifford DK, Whiteway M, Giaever G, Nislow C, Costanzo M, Gingras AC, Mitra RD, Andrews B, Fink GR, Cowen LE, Boone $C$ : Global gene deletion analysis exploring yeast filamentous growth. Science 2012, 337(6100):1353-1356.

28. Reynolds TB, Fink GR: Bakers' yeast, a model for fungal biofilm formation. Science 2001, 291(5505):878-881.

29. Vachova L, Stovicek V, Hlavacek O, Chernyavskiy O, Stepanek L, Kubinova L, Palkova Z: Flo11p, drug efflux pumps, and the extracellular matrix cooperate to form biofilm yeast colonies. J Cell Biol 2011, 194(5):679-687

30. Weiss Nielsen M, Sternberg C, Molin S, Regenberg B: Pseudomonas aeruginosa and Saccharomyces cerevisiae biofilm in flow cells. J Vis Exp 2011, 47:pii: 2383.

31. Granek JA, Murray D, Kayrkci O, Magwene PM: The genetic architecture of biofilm formation in a clinical isolate of Saccharomyces cerevisiae. Genetics 2013, 193(2):587-600.

32. Vandenbosch D, De Canck E, Dhondt I, Rigole P, Nelis HJ, Coenye T: Genomewide screening for genes involved in biofilm formation and miconazole susceptibility in Saccharomyces cerevisiae. FEMS Yeast Res 2013, 13(8):720-730

33. Scherz K, Andersen Bojsen R, Gro L, Rejkjaer S, Weiss M, Nielsen Lisby M, Folkesson A, Regenberg B: Genetic basis for Saccharomyces cerevisiae biofilm in liquid medium. G3 (Bethesda) 2014, 4(9):1671-1680.

34. Tristezza M, Lourenco A, Barata A, Brito L, Malfeito-Ferreira M, Loureiro V: Susceptibility of wine spoilage yeasts and bacteria in the planktonic state and in biofilms to disinfectants. Ann Microbiol 2010, 60(3):549-556.

35. Chandra J, Kuhn DM, Mukherjee PK, Hoyer LL, McCormick T, Ghannoum MA: Biofilm formation by the fungal pathogen Candida albicans: development, architecture, and drug resistance. J Bacteriol 2001, 183(18):5385-5394.

36. Enache-Angoulvant $A$, Hennequin C: Invasive Saccharomyces infection: a comprehensive review. Clin Infect Dis 2005, 41(11):1559-1568,

37. Ramage G, Mowat E, Jones B, Williams C, Lopez-Ribot J: Our current understanding of fungal biofilms. Crit Rev Microbiol 2009, 35(4):340-355.
38. Mah TF, OToole GA: Mechanisms of biofilm resistance to antimicrobial agents. Trends Microbiol 2001, 9(1):34-39.

39. Nguyen D, Joshi-Datar A, Lepine F, Bauerle E, Olakanmi O, Beer K, McKay G, Siehnel R, Schafhauser J, Wang Y, Britigan BE, Singh PK: Active starvation responses mediate antibiotic tolerance in biofilms and nutrient-limited bacteria. Science 2011, 334(6058):982-986.

40. Spoering AL, Lewis K: Biofilms and planktonic cells of Pseudomonas aeruginosa have similar resistance to killing by antimicrobials. J Bacterio 2001, 183(23):6746-6751

41. Anderl JN, Zahller J, Roe F, Stewart PS: Role of nutrient limitation and stationary-phase existence in Klebsiella pneumoniae biofilm resistance to ampicillin and ciprofloxacin. Antimicrob Agents Chemother 2003, 47(4):1251-1256.

42. Millard PJ, Roth BL, Thi HP, Yue ST, Haugland RP: Development of the FUN-1 family of fluorescent probes for vacuole labeling and viability testing of yeasts. Appl Environ Microbio/ 1997, 63(7):2897-2905.

43. Haagensen JA, Regenberg B, Sternberg C: Advanced microscopy of microbial cells. Adv Biochem Eng Biotechnol 2011, 124:21-54.

44. Beauvais A, Loussert C, Prevost MC, Verstrepen K, Latge JP: Characterization of a biofilm-like extracellular matrix in FLO1-expressing Saccharomyces cerevisiae cells. FEMS Yeast Res 2009, 9(3):411-419.

45. Verstrepen KJ, Reynolds TB, Fink GR: Origins of variation in the fungal cell surface. Nat Rev Microbiol 2004, 2(7):533-540.

46. Guo B, Styles CA, Feng Q, Fink GR: A Saccharomyces gene family involved in invasive growth, cell-cell adhesion, and mating. Proc Natl Acad SC U S A 2000, 97(22):12158-12163.

47. Mitchell KF, Taff HT, Cuevas MA, Reinicke EL, Sanchez H, Andes DR: Role of matrix beta-1,3 glucan in antifungal resistance of non-albicans Candida biofilms. Antimicrob Agents Chemother 2013, 57(4):1918-1920.

48. Nett JE, Crawford K, Marchillo K, Andes DR: Role of Fks1p and matrix glucan in Candida albicans biofilm resistance to an echinocandin, pyrimidine, and polyene. Antimicrob Agents Chemother 2010, 54(8):3505-3508.

49. Baillie GS, Douglas LJ: Matrix polymers of Candida biofilms and their possible role in biofilm resistance to antifungal agents. J Antimicrob Chemother 2000, 46(3):397-403

50. Pamp SJ, Gjermansen M, Johansen HK, Tolker-Nielsen T: Tolerance to the antimicrobial peptide colistin in Pseudomonas aeruginosa biofilms is linked to metabolically active cells, and depends on the pmr and mexAB-oprM genes. Mol Microbiol 2008, 68(1):223-240.

51. Martinez LR, Casadevall A: Susceptibility of Cryptococcus neoformans biofilms to antifungal agents in vitro. Antimicrob Agents Chemother 2006, 50(3):1021-1033

52. Levin BR, Rozen DE: Non-inherited antibiotic resistance. Nat Rev Microbiol 2006, 4(7):556-562

53. Lewis RE, Klepser ME, Pfaller MA: In vitro pharmacodynamic characteristics of flucytosine determined by time-kill methods. Diagn Microbiol Infect Dis 2000, 36(2):101-105.

54. Bartizal K, Gill CJ, Abruzzo GK, Flattery AM, Kong L, Scott PM, Smith JG, Leighton CE, Bouffard A, Dropinski JF, Balkovec J: In vitro preclinical evaluation studies with the echinocandin antifungal MK-0991 (L-743,872). Antimicrob Agents Chemother 1997, 41(11):2326-2332.

55. Frost DJ, Brandt K, Capobianco J, Goldman R: Characterization of $(1,3)-$ beta-glucan synthase in Candida albicans: microsomal assay from the yeast or mycelial morphological forms and a permeabilized whole-cell assay. Microbiology 1994, 140(Pt 9):2239-2246.

56. Perlin DS: Current perspectives on echinocandin class drugs. Future Microbiol 2011, 6(4):441-457.

57. Klepser ME, Malone D, Lewis RE, Ernst EJ, Pfaller MA: Evaluation of voriconazole pharmacodynamics using time-kill methodology. Antimicrob Agents Chemother 2000, 44(7):1917-1920.

58. Anderson JB: Evolution of antifungal-drug resistance: mechanisms and pathogen fitness. Nat Rev Microbiol 2005, 3(7):547-556.

59. Folkesson A, Haagensen JA, Zampaloni C, Sternberg C, Molin S: Biofilm induced tolerance towards antimicrobial peptides. PLoS One 2008, 3(4):e1891

60. Liu Y, Knapp KM, Yang L, Molin S, Franzyk H, Folkesson A: High in vitro antimicrobial activity of beta-peptoid-peptide hybrid oligomers against planktonic and biofilm cultures of Staphylococcus epidermidis. Int J Antimicrob Agents 2013, 41(1):20-27.

61. Zuroff TR, Bernstein H, Lloyd-Randolfi J, Jimenez-Taracido L, Stewart PS, Carlson RP: Robustness analysis of culturing perturbations on Escherichia 
coli colony biofilm beta-lactam and aminoglycoside antibiotic tolerance. BMC Microbiol 2010, 10:185.

62. Partow S, Siewers V, Bjorn S, Nielsen J, Maury J: Characterization of different promoters for designing a new expression vector in Saccharomyces cerevisiae. Yeast 2010, 27(11):955-964.

63. Andersen JB, Sternberg C, Poulsen LK, Bjorn SP, Givskov M, Molin S: New unstable variants of green fluorescent protein for studies of transient gene expression in bacteria. Appl Environ Microbiol 1998, 64(6):2240-2246.

64. Geu-Flores F, Nour-Eldin HH, Nielsen MT, Halkier BA: USER fusion: a rapid and efficient method for simultaneous fusion and cloning of multiple PCR products. Nucleic Acids Res 2007, 35(7):e55.

65. Nour-Eldin HH, Hansen BG, Norholm MH, Jensen JK, Halkier BA: Advancing uracil-excision based cloning towards an ideal technique for cloning PCR fragments. Nucleic Acids Res 2006, 34(18):e122.

66. Mikkelsen MD, Buron LD, Salomonsen B, Olsen CE, Hansen BG, Mortensen UH, Halkier BA: Microbial production of indolylglucosinolate through engineering of a multi-gene pathway in a versatile yeast expression platform. Metab Eng 2012, 14(2):104-111.

67. Gietz RD, Woods RA: Yeast transformation by the LiAc/SS Carrier DNA/PEG method. Methods Mol Biol 2006, 313:107-120.

68. Sherman F: Getting started with yeast. Methods Enzymol 1991, 194:3-21.

69. EUCAST: EUCAST definitive document EDef 7.1: method for the determination of broth dilution MICs of antifungal agents for fermentative yeasts. Clin Microbiol Infect 2008, 14(4):398-405.

doi:10.1186/s12866-014-0305-4

Cite this article as: Bojsen et al:: Saccharomyces cerevisiae biofilm

tolerance towards systemic antifungals depends on growth phase. BMC

Microbiology 2014 14:305.

\section{Submit your next manuscript to BioMed Central and take full advantage of:}

- Convenient online submission

- Thorough peer review

- No space constraints or color figure charges

- Immediate publication on acceptance

- Inclusion in PubMed, CAS, Scopus and Google Scholar

- Research which is freely available for redistribution 